\title{
An evaluation study of the degree of need for classification criteria for Jordanian universities from the point of view of administrative academics in Jordanian universities
}

\author{
Dr. Khawla Al-Sani ${ }^{1, *}$, Fursan Thabit ${ }^{2}$
}

\author{
${ }^{1}$ School of Management, The University of Jordan, Jordan \\ ${ }^{2}$ School of Computational Sciences, S.R.T.M. University, Nanded, India
}

Received: 24 Jan 2021; Received in revised form: 21 Mar 2021; Accepted: 29 Apr 2021; Available online: 10 May 2021 (C)2021 The Author(s). Published by Infogain Publication.

\begin{abstract}
The study aimed to find out the degree of availability of classification criteria for Jordanian universities from the point of view of administrative academics in them, and in order to achieve the objectives of the study, a questionnaire consisting of (42) paragraphs was constructed whose validity and reliability was verified, and it was distributed to the study sample consisting of (141) deans, their deputies and heads of departments in University of Jordan. As it retrieved (100) questionnaires. The results showed that the availability of classification criteria for universities in the University of Jordan as a whole was medium, as the highest was for the sixth field "Results and Achievements" with an arithmetic average of (3.88) and with a high degree of availability, and in the last rank the seventh field "Information and its analysis" with an arithmetic average of (3.12) and a moderate degree of availability. The results showed that there were no statistically significant differences in the overall score indicating the differences in the fields of the university classification criteria according to the job title variable, as well as in the fields of the university classification criteria.
\end{abstract}

The study recommended issuing an introductory yearbook for the University of Jordan and its achievements and enabling leaders at the University of Jordan to undertake strategic planning.

Keywords-Evaluation Study, Classification Criteria, Administrative Academics.

\section{INTRODUCTION}

The third millennium is witnessing an explosion of knowledge, which made countries face various challenges, so I was keen to mobilize all material and human capabilities to confront global competition and to enter the global race track, and from the community institutions that have come to face global competition, universities as they are a tool of society, so I was forced to review All its systems and regulations, restructuring its units, improving its outputs, and developing its competitive capabilities in line with the pressures from competitors from all over the world.In recent years, some research centers have begun to measure the efficiency and quality of university institutions by issuing continuous reports that determine the extent to which these universities adhere to specific global standards (Ghabboub, 2016). Announcing the results of the rankings of universities and higher education institutions worldwide every year is highly anticipated. Because the ranks obtained by the ranked universities largely reflect the level of progress of their countries, and this interest is no longer confined to the developed countries where the world-class universities are located, but some developing countries have begun to follow with great interest the results of these classifications (Al-Abbad, 2017).

This work is licensed under a Creative Commons Attribution 4.0 License. http://creativecommons.org/licenses/by/4.0/ 
The ranking of universities at the global level is one of the most important means of evaluating them and demonstrating their quality, whether in terms of scientific research, teaching, or the education they provide. Despite the different indicators used by these classifications, the first universities in the world often maintain their place in the front ranks in the rankings, such as Harvard University, Massachusetts Institute of Technology, Stanford University, University of California, and University of Oxford (Al-Siddiqi, 2015).

The absence of Arab universities from the global list of the best universities is an indication of the low ranking of Arab universities in the international rankings, an indication of the deterioration of the quality of education and its outputs in the Arab world, which poses a challenge to those in charge of universities in order to improve the ranking of universities in the Arab world and internationally (Ghabboub, 2016). Based on the above, this study came with the aim of evaluating the degree of need for classification criteria for Jordanian universities from the point of view of their administrative academics.

\section{RESEARCH PROBLEM}

In view of the intense rivalry between the countries of the world to take the lead in the field of the information economy, it is no longer possible to disregard universities' global rankings, as the countries that receive many of their universities on advanced world rankings have become a weapon that attracts international students. from all over the world.

Those who follow the position of Jordanian universities in the international rankings will notice that it is very weak. The Times Higher Education World University Ranking Of 2016-2017 report The University of Jordan ranked between 801-1000, while the University of Science and Technology ranked between 601- 800 (2017, Times Higher Education World University Rankings) While the report of the Spanish Center for WebMetrics for the year 2016 indicated that the University of Jordan ranked 1220, 41 in the Middle East, while the University of Science and Technology ranked 1729, and at the level of the Middle East 76 (2016 Webometrics of World Universities Ranking).

The World Bank report also indicated that higher education systems in the Middle East are facing pressures due to the quality gap between the skills sought by the labor market and the skills acquired by university graduates. Arab universities need innovation in order to provide an education that enables their graduates to become competitors and contributors to development (the Bank International, 2010).
The problem of this study is determined in defining the "degree of need for classification criteria for Jordanian universities from the point of view of their administrative academics."

The study problem can therefore be summarized in replying to the following questions:

1- What is the degree of availability of university classification criteria at the University of Jordan from the point of view of its administrative academics?

2- What is the importance of providing classification criteria for universities at the University of Jordan from the point of view of its administrative academics?

3- What is the degree of need to provide classification criteria for universities at the University of Jordan based on the difference between the degree of availability and the degree of importance attributable to the variable of job rank?

\section{RESEARCH OBJECTIVE}

The study centered on the degree of need for Jordanian university classification requirements from the academic point of view of the administrators within it.

\section{- Importance of studying}

The results of this study are as follows:

Employing the results of the study and disseminating them to Jordanian universities. It is hoped that an introduction will benefit from it, a role in future projects in this context.

\section{- Terminology of study}

The study adopts the following terms: An evaluation study: a study of quality indicators and Jordanian universities.

- University Rankings: A process by which universities and educational and academic institutions are arranged in a sequential manner according to the classification body that undertakes this task and on the basis of the criteria and indicators adopted in this regard, and there are many trends and institutions in the world that undertake this task (Wildavsky, 2010). As for procedural, it is: the degree obtained by the sample members of the academic administrators at the University of Jordan through their answers to the paragraphs of the "Jordanian Universities Ranking" scale used in this study

- Classification criteria:

Ahmed (2012) defined them as the levels related to competencies required to be met in all educational programs offered by educational 
institutions, and these criteria differ according to the classification body.

As for the procedures, they are: The competencies that must be provided in Jordanian universities in order to join the higher level and perform their function in society.

- Administrative academics: They are the deans of the colleges, their deputies, and the heads of departments in the official Jordanian universities.

\section{The limits of the study}

The study includes the following limits:

- Human Limits: The study was limited to administrative academics.

- Time limits: This study was conducted on the 2018/2019 academic year.

- Spatial boundaries: The study was limited to the University of Jordan.

\section{Theoretical framework:}

The theoretical framework consists of an introduction to the emergence and development of university rankings, followed by an enumeration of the most important university rankings.

The emergence and development of university rankings The first roots of university classification attempts go back to 1904 in Britain, where studies appeared trying to provide a list of several universities arranged according to the number of pioneers and scholars who graduated from them, and in the United States of America, "Gibbs Michael Cattel" issued a list of colleges, which he called "Leading" Institutions "in an attempt to familiarize students and help them define their academic choices. Stephen Fisher analyzed that list in 1920, and a group of scholars were influenced by what both Cattle and Fisher wrote.

In 1951, the American Universities Union requested a study on the classification of colleges, and 344 higher education institutions were classified and divided into four groups, and a summary of that classification was published in newspapers, which provoked reactions that reached the demand to close the union, and the result of that was the suspension of these attempts. Until 1959, when the University of Pennsylvania conducted an initiative to compare universities in the United States of America by conducting a survey based on the popularity of these universities, in which the opinions of department heads were taken in 35 universities, and they ranked the best 15 departments in 25 universities, and they were classified into four areas of humanity. Social sciences, natural sciences, biology, and from that year until 1966 there was a growing interest in making classifications (Luke \& Robe, 2009).

\section{Most famous university rankings:}

Among the most famous university rankings in academic and administrative circles:

1. Ranking of Shanghai Jiao Jong University A classification issued by Shanghai Jiao Tong University, which is known as the Academic Ranking of World Universities (ARWU). The first ranking was issued in 2003 by the University's Institute of Higher Education, and the aim of issuing it was to know the location of Chinese universities among International universities in terms of academic performance and scientific research. The classification depends on the university's scientific production rate, and on the extent of its obtaining the Nobel Prize or the best-known field for mathematics.

The classification method includes four criteria, which are as follows:

First: The quality of education: represented by the Nobel Prize winners or prizes in the quality of mathematics education. \% 10.

Second: the competence of faculty members: represented in the percentage of those who win the Nobel Prize or Field Awards in mathematics quality $20 \%$ and the percentage of recourse and citation of their research. \% 20.

Third: Academic achievement: compared to the size of the scientific institution, represented by the university's performance in relation to its size. \%

Fourth: Research production: represented in the number of papers published in the two journals of Nature and Science $20 \%$, and the research mentioned in the reference book for the social sciences and the expanded reference 20\%. (Salmi, 2013).

The researcher believes that this classification is concerned with the natural sciences at the expense of other sciences, in addition to being concerned with individual projects, and this is not considered an indication of the quality of performance.

\section{THE World Ranking: The TIMES- QS}

This comes from a professional education company called Quacquarelli Symonds, which was founded in 1990 and aims to raise global standards for higher education. And obtaining information about the study program in various universities, especially in the fields of science and technology, and making a comparison for the best (500) universities among more than (30) thousand universities around the world with the aim of issuing a guide that helps students and professional companies choose universities. 
This classification is based on six indicators, which are as follows:

a. Peer evaluation: Academic Peer Review, with a rate of $40 \%$.

B. The percentage of faculty members for students is $20 \%$.

C. Academic research and reference Citations Per Faculty, and its rate is $20 \%$.

Dr. The Employer Review labor market calendar and its $10 \%$ rate.

H. For foreign professors, the rate is $5 \%$.

And. International Students, a rate of 5\% (Al-Sayegh, 2010).

\section{Webometrics Spanish classification}

This classification is issued by the Cybermetricslab Studies Unit of the largest research institution in Spain, the Spanish Center for the Evaluation of Universities and Institutes, which is a center of the Spanish Ministry of Education, and publishes its results on www.webmetrics.info 2004, and depends on monitoring the movement of academic websites and the most advanced electronic pages in the field of research. Studies and reports; It aims to urge the academic authorities in the world to present their scientific activities in a way that reflects their distinguished scientific level on the Internet.

This classification is issued every six months. As for the criteria for this classification, they are the following:

1. The university's global performance and visibility of the university

It includes the following indications:

A- Web Size, which means the size of the university's website pages, according to the periodic reports issued by the four search engines (Google, Yahoo, Alexa, and Live) and its percentage is $20 \%$.

B. Rich files standard, where the number of files of various types, whether in (pdf), (document) or (presentation) type, is calculated and is monitored by search engines, and its rate is $15 \%$.

C. Research criterion (Scholar), where the number of published research is calculated electronically under the scope of the university's website and its rate is $15 \%$.

2. Impact: It is measured through the Link Impact and Visibility (Isidro \& Agullio, 2008).

\section{Previous studies related to the subject of the study:}

This part deals with a presentation of previous studies related to the subject of the study:

Amal Akl (2005) conducted a study aimed at developing standards of excellence for the university level in higher education institutions in Jordan. A questionnaire consisting of 103 items was developed and distributed to (230) members of the study community consisting of deans, department heads and directors of administrative units. The study showed the following results: The absence of statistically significant differences attributed to the university variable, and the existence of statistically significant differences due to the variable of job title and experience, and the study also showed that the degree of evaluation of the study sample for the areas of classification was high and the highest was the field of leadership.

Sheil (2010) conducted a study aimed at uncovering the reasons for the development of the university system in Australia beyond the international rankings of higher education institutions. The results showed that the most important of these reasons is the focus on providing resources and financial support, developing information systems in universities, ensuring diversity in educational methods and techniques, and training Qualifying academic bodies, and strengthening university administrative bodies.

Carroll (2014) also conducted a study aimed at knowing the relationship between university classification and some measures in higher education such as the level of fees and research support according to the classification known in Australia as the Group of Eight (Group of eight, where the study adopted the descriptive approach, and the study showed that there is a positive effect. These rankings include the level of graduates of these universities and their employment, the research performance of faculty members, attendance at international conferences and seminars, electronic services and advanced technologies and their use in education.

Houria's study (2013) also aimed to know the reality of planning to prepare a Taibah University to achieve global university ranking policies, and to come up with a proposed vision to prepare Taibah University to achieve global university ranking policies. The study adopted the qualitative approach, as qualitative interviews were conducted with an intentional sample of 14 respondents, all of whom were decision-makers and faculty members at Taibah University in Medina, from various colleges of the university. The study found a consensus on classification policies among international ranking institutions for universities in terms of objectives, methods of data collection, and the criteria and indicators used in classification. It also found that there is a general trend in the university to compete in the world university rankings. The study revealed that there is a weakness in the standards of the rankings, which may prevent the university from participating in the international rankings 
of universities, related to human resources, administrative aspects, and financial aspects.

Barakat (2016) conducted a survey study aimed at knowing the opinion of a sample of administrative and academic workers in some Palestinian universities about the dimensions of the proposed strategy to prepare these universities for the international classification of universities. This sample consisted of (192) individuals on whom a questionnaire was applied consisting of (37) paragraphs representing each Of these, an element of the proposed strategy is divided into three areas: the first is related to human resources, the second relates to the financial aspect, and the third relates to the administrative and academic aspect. The results of the study showed that the estimates of the study sample individuals for the different elements in the three areas were at a high level, and the results showed that there were no statistically significant differences in the level of the study sample's estimates on the proposed strategic areas to prepare Palestinian universities for the international classification of universities according to the variables: gender, specialization, and qualification. Scientific, academic rank, experience, and scientific rank.

Al-Abbad (2017) studied the study aimed at presenting the identification of requirements for raising the competitiveness of King Saud University in light of the international application standards for universities, and the study adopted the descriptive approach by analyzing the lists of international rankings that included the ranking of some Saudi universities such as Webo matrix, the SCImag universities research classification and the Shanghai classification For the year 2014 and the global designation of universities in 2015, it also relied on analyzing the experiences and experiences of some leading models such as Harvard University, and the study presented the axes of excellence based on the strategic planning of the university in light of the Kingdom's 2030 vision, and information for economic and societal development.

\section{Previous studies and the location of the current study,} including:

The researcher was able to review a set of previous studies related to the subject of the study, "an evaluation study of the degree of need for classification criteria for Jordanian universities from the point of view of the administrative academics in them." For previous studies, the subject of the study, and the location of the current study, including:

- Previous studies have dealt with classification in universities and have adopted various curricula such as the qualitative one: such as the study of Houry (2013), including those that have adopted the descriptive curriculum as the study: Al-Abad (2017), Barakat study (2016), Carroll study (2014), and Amal Aql study (2005) Also, the current study adopted the descriptive method.

The tools of the previous studies are covered in the questionnaire, such as: Barakat's study (2016), Carroll's study (2014), and Amal Akl study (2005), as well as the current study using the questionnaire.

- This study was distinguished from other previous studies by the researcher studying "an evaluation study of the degree of need for classification criteria for Jordanian universities from the point of view of administrative academics in them" with the aim of raising their efficiency and achieving their quality, which was not carried out by any previous study within the limits of the researcher's knowledge.

\section{Study methodology and procedures:}

\section{Study Approach:}

The researcher used the descriptive approach to suit the purposes of the study, and a questionnaire was used to collect the study data.

\section{Study population:}

The study population consisted of all deans, their deputies, and department heads in Jordanian universities. And their number (789).

\section{The study sample:}

An intentional sample was chosen, which is the University of Jordan, and (141) questionnaires were distributed to the academic administrators at the University of Jordan, from which (100) were retrieved. This statistic was obtained from the Ministry of Higher Education website 2017/2018, distributed as follows:

Table.1. Distribution of study sample individuals for the three levels according to the job title variable (dean, deputy dean, department head)

\begin{tabular}{lrcrc}
\hline University & \multicolumn{4}{c}{ Job title } \\
\cline { 2 - 5 } Name & Dean & $\begin{array}{l}\text { Deputy } \\
\text { Dean, }\end{array}$ & Head & Total \\
$\begin{array}{l}\text { The } \\
\text { University } \\
\text { Jordan }\end{array}$ & 22 & 30 & 89 & 141 \\
\hline
\end{tabular}




\begin{tabular}{|c|c|c|c|}
\hline No & field & $\begin{array}{l}\text { Number of } \\
\text { paragraphs }\end{array}$ & $\begin{array}{l}\text { Cronbach's } \\
\text { alpha, } \alpha\end{array}$ \\
\hline 1 & Leadership & 6 & 0.88 \\
\hline 2 & Strategic Planning & 6 & 0.72 \\
\hline 3 & External focus & 7 & 0.76 \\
\hline 4 & $\begin{array}{l}\text { Information and its } \\
\text { analysis }\end{array}$ & 7 & 0.83 \\
\hline 5 & Teaching staff & 5 & 0.81 \\
\hline 6 & $\begin{array}{ll}\text { Results and } \\
\text { achievements }\end{array}$ & 6 & 0.78 \\
\hline \multirow[t]{2}{*}{7} & Pointers & 5 & 0.77 \\
\hline & Total marks & 42 & 0.84 \\
\hline
\end{tabular}

\section{Stability Of The Study Tool:}

After preparing the tool in its final form, the stability parameter was extracted using the Cronbach Alpha equation for the internal consistency of the fields of the study tool, and It appears from Table (2):

- That the Kronbach alpha coefficients for the fields "to the degree of the need for classification criteria for Jordanian universities from the point of view of administrative academics in them" ranged between (0.88-0.72), the highest was in the field of "leadership", and the lowest was in the field of "strategic planning", and the Cronbach alpha coefficient reached the degree of need for classification criteria for universities Jordan as a whole (0.84); And all the stability coefficients are high and acceptable for the purposes of the study, where the stability coefficient (Cronbach Alpha) is acceptable if it exceeds (0.70).

Scale correction:

The questionnaire consisted in its final form of (42) paragraphs, where the researcher used the Table (2) shows the values of the stability coefficients for the fields of the study tool, which are considered acceptable for the purposes of the study.Likert scale of the five-point gradient in order to measure the opinions of the study sample members, and agreement was given to a very large degree (5), highly agree (4), agree with a medium degree (3), agree with a degree Few (2), agree very little (1), by placing a sign () in front of the answer that reflects the degree of their agreement, and the following classification has been relied on to judge the arithmetic averages as follows:

-Less than 2.33 a few.

- from 2.34-3.66 medium.

-From 3.67 to 5.00 high.

\section{Statistical Treatment:}

To answer the study questions, the following statistical treatments were used through the Statistical Packages Program (SPSS):

Frequencies and percentages of job variables for the study sample.

- Cronbach internal consistency coefficient alpha for all fields of study and Pearson correlation coefficient. To extract the replay constancy.

- The arithmetic means and standard deviations of the answers of the study sample individuals for all areas of the study tool.

One-way-ANOVA.

\section{Study Results and Discussion}

This part includes a detailed presentation of the statistical analysis of the results of the study, which aims to define the degree of availability of classification criteria for universities at the University of Jordan from the point of view of administrative academics and discuss them, and these results will be presented based on the assumptions of the study.

Results related to the answer to the first question: What is the degree of availability of university ranking criteria at the University of Jordan from the point of view of its administrative academics?

To answer this question, arithmetic averages and deviations were calculated for each field of "degree of availability of ranking criteria for universities at the University of Jordan" and "degree of availability of classification criteria for universities in the University of Jordan" as a whole. Table (3) illustrates this:

Table.3: The arithmetic averages and standard deviations for the domains of the degree that provide classification criteria for universities at the University of Jordan, and the degree of availability of classification criteria for universities in the University of Jordan, as a whole, ranked in descending order $(n=100)$

\begin{tabular}{clcccc}
\hline No & field & AV & \multicolumn{1}{l}{$\alpha$} & $\mathrm{R}$ & $\mathrm{D} \mathrm{V}$ \\
\hline $\mathbf{6}$ & Results and achievements & 3.88 & .535 & 1 & $\mathrm{H}$ \\
$\mathbf{5}$ & Teaching staff & 3.83 & .553 & 2 & $\mathrm{H}$ \\
$\mathbf{1}$ & Leadership & 3.81 & .300 & 3 & $\mathrm{H}$ \\
$\mathbf{7}$ & Pointers & 3.69 & .624 & 4 & $\mathrm{H}$ \\
$\mathbf{3}$ & External focus & 3.59 & .535 & 5 & $\mathrm{M}$ \\
$\mathbf{2}$ & Strategic Planning & 3.55 & .553 & 6 & $\mathrm{M}$ \\
$\mathbf{4}$ & Information and its & 3.12 & .464 & 7 & $\mathrm{M}$ \\
& analysis & & & & \\
$\mathbf{4}$ & A degree that provides & $\mathbf{3 . 6 4}$ & $\mathbf{. 3 7 2}$ & - & $\mathbf{M}$ \\
\hline
\end{tabular}


classification criteria for universities in the University of Jordan "as a whole."

\begin{tabular}{|c|c|c|c|c|c|}
\hline 3 & External focus & 4.80 & 0.279 & 2 & $\mathrm{H}$ \\
\hline 6 & $\begin{array}{ll}\text { Results } & \text { and } \\
\text { achievements } & \end{array}$ & 4.79 & 0.363 & 3 & $\mathrm{H}$ \\
\hline 4 & $\begin{array}{l}\text { Information and its } \\
\text { analysis }\end{array}$ & 4.77 & 0.122 & 4 & $\mathrm{H}$ \\
\hline 5 & Teaching staff & 4.68 & 0.189 & 5 & $\mathrm{H}$ \\
\hline \multirow[t]{2}{*}{2} & Strategic Planning & 4.58 & 0.184 & 6 & $\mathrm{H}$ \\
\hline & $\begin{array}{l}\text { A degree that } \\
\text { provides } \\
\text { classification criteria } \\
\text { for universities in the } \\
\text { University of Jordan } \\
\text { "as a whole." }\end{array}$ & 4.74 & 0.096 & - & $\mathrm{H}$ \\
\hline
\end{tabular}

Table (4) shows that the arithmetic averages for the fields of "the importance of providing classification criteria for universities at the University of Jordan" ranged between (5.00-4.58), the highest was for the third field "leadership" with an arithmetic mean of (5.00) and with a high degree of importance of availability, followed by the seventh field.

The indicators with an arithmetic average of (4.86) and a high degree of importance of availability, and with a high degree of importance, and in the last place in the fourth field, "strategic planning," with an arithmetic mean of (4.58) and a high degree of importance of availability. Availability importance is high, The results related to the answer to the third question: What is the degree of need for the availability of classification criteria for universities at the University of Jordan based on the difference between the degree of availability and the degree of importance attributable to the variable of job rank

To answer this question, arithmetic averages and standard deviations were calculated for the need for each field of classification criteria for universities according to job title, and the results showed that there are only apparent differences in these averages Table (5), and to know the significance of these differences, the One Way ANOVA analysis was used. ), As in Table (5).

Table.5: Averages and standard deviations of the differences between the importance and reality of the classification criteria for universities according to the job title variable.

\begin{tabular}{lccccc}
\hline & Field & Job Title & NO & AVR & $\alpha$ \\
\hline Leadership & Dean & 16 & 0.83 & .350 \\
& & Deputy Dean & 28 & 0.92 & .233 \\
\hline
\end{tabular}




\begin{tabular}{|c|c|c|c|c|}
\hline & Head Dept. & 56 & .83 & .314 \\
\hline \multirow[t]{3}{*}{ Strategic Planning } & Dean & 16 & 1.04 & .493 \\
\hline & Deputy Dean & 28 & 1.00 & .456 \\
\hline & Head Dept. & 56 & 1.04 & .530 \\
\hline \multirow[t]{3}{*}{ External focus } & Dean & 16 & 1.13 & 699 \\
\hline & Deputy Dean & 28 & 1.18 & .585 \\
\hline & Head Dept. & 56 & 1.24 & .578 \\
\hline \multirow[t]{3}{*}{ Information and its analysis } & Dean & 16 & 1.56 & .582 \\
\hline & Deputy Dean & 28 & 1.70 & .452 \\
\hline & Head Dept. & 56 & 1.65 & .442 \\
\hline \multirow[t]{3}{*}{ Teaching staff } & Dean & 16 & 0.74 & .714 \\
\hline & Deputy Dean & 28 & 0.84 & .415 \\
\hline & Head Dept. & 56 & 0.90 & .638 \\
\hline \multirow[t]{3}{*}{ Results and achievements } & Dean & 16 & 0.95 & .547 \\
\hline & Deputy Dean & 28 & 0.88 & .652 \\
\hline & Head Dept. & 56 & 0.96 & .659 \\
\hline \multirow[t]{3}{*}{ Pointers } & Dean & 16 & 1.28 & .473 \\
\hline & Deputy Dean & 28 & 1.06 & .678 \\
\hline & Head Dept. & 56 & 1.19 & .709 \\
\hline \multirow[t]{3}{*}{ Total marks } & Dean & 16 & 1.08 & .366 \\
\hline & Deputy Dean & 28 & 1.08 & .307 \\
\hline & Head Dept. & 56 & 1.11 & .396 \\
\hline
\end{tabular}

Table.6: Results of a single variance analysis of differences indicating the fields of the universities' classification criteria according to the job title variable

\begin{tabular}{|c|c|c|c|c|c|c|}
\hline Field & $\begin{array}{c}\text { The source of the } \\
\text { contrast }\end{array}$ & $\begin{array}{l}\text { Sum of } \\
\text { squares }\end{array}$ & $\begin{array}{l}\text { Degrees of } \\
\text { freedom }\end{array}$ & $\begin{array}{l}\text { Average of } \\
\text { squares }\end{array}$ & Value $(\mathrm{P})$ & $\begin{array}{c}\text { Indication } \\
\text { level }\end{array}$ \\
\hline \multirow[t]{3}{*}{ Leadership } & Between Group & .169 & 2 & .085 & .941 & .394 \\
\hline & Inside Group & 8.721 & 97 & .090 & & \\
\hline & Sum & 8.890 & 99 & & & \\
\hline \multirow[t]{3}{*}{ Strategic Planning } & Between Group & .035 & 2 & .017 & .069 & .934 \\
\hline & Inside Group & 24.708 & 97 & .255 & & \\
\hline & Sum & 24.743 & 99 & & & \\
\hline \multirow[t]{3}{*}{ External focus } & Between Group & .159 & 2 & .079 & .220 & .803 \\
\hline & Inside Group & 34.954 & 97 & .360 & & \\
\hline & Sum & 35.112 & 99 & & & \\
\hline Information and its & Between Group & .204 & 2 & .102 & .464 & .630 \\
\hline
\end{tabular}




\begin{tabular}{|c|c|c|c|c|c|c|}
\hline \multirow[t]{2}{*}{ analysis } & Inside Group & 21.317 & 97 & .220 & & \\
\hline & Sum & 21.521 & 99 & & & \\
\hline \multirow[t]{3}{*}{ Teaching staff } & Between Group & .327 & 2 & .164 & .457 & .634 \\
\hline & Inside Group & 34.701 & 97 & .358 & & \\
\hline & Sum & 35.028 & 99 & & & \\
\hline \multirow{3}{*}{$\begin{array}{l}\text { Results and } \\
\text { achievements }\end{array}$} & Between Group & .134 & 2 & .067 & .163 & .850 \\
\hline & Inside Group & 39.866 & 97 & .411 & & \\
\hline & Sum & 40.000 & 99 & & & \\
\hline \multirow[t]{3}{*}{ Pointers } & Between Group & .502 & 2 & .251 & .560 & .573 \\
\hline & Inside Group & 43.423 & 97 & .448 & & \\
\hline & Sum & 43.924 & 99 & & & \\
\hline \multirow[t]{3}{*}{ Total marks } & Between Group & .029 & 2 & .015 & .108 & .897 \\
\hline & Inside Group & 13.191 & 97 & .136 & & \\
\hline & Sum & 13.220 & 99 & & & \\
\hline
\end{tabular}

Table (6) shows that there are no statistically significant differences in the overall degree to indicate the differences in the fields of university classification criteria according

Discussing the results: Related to the answer to the first question: What is the degree of availability of ranking criteria for universities at the University of Jordan from the point of view of its administrative academics? The results were as follows:

The degree of availability of university classification criteria at the University of Jordan "was medium, with an arithmetic average (3.64), and a standard deviation (.372). The field of" results and achievements "came in the first rank with an arithmetic average of (3.88) with a high degree of availability, and in the last rank. Information and its analysis "with an arithmetic average of (3.12) and with a moderate degree of availability. This result may be attributed to the lack of Jordanian universities, including the University of Jordan, for a clear strategic vision that would improve their academic ranking at the global level, and this may be attributed to the low spending on scientific research, and this may be attributed to the low wages of faculty members.

The result of this study differs with that of Barakat's study (2016).

The achievement of the field of "results and achievements" in the first place may be attributed to the study sample's belief that concern for students and to the job title variable, as well as in the fields of university classification criteria.

beneficiaries and meeting their needs and expectations will reflect positively on the educational institution and thus achieve its goals.

The results of this study differ with that of Amal Akl (2005).

\section{Discussing the results related to the answer to the} second question:

What is the importance of providing ranking criteria for universities at the University of Jordan from the point of view of its administrative academics? ? The results were as follows:

The importance of providing classification criteria for universities at the University of Jordan was high, the highest being for the third field "leadership" and with a high degree of availability, and in the last place for the fourth field "strategic planning" and with a high degree of importance. It may be attributed to the University of Jordan's keenness to be in the forefront of world classifications.

And it came in the first rank in the field: "Leadership." This may be due to the fact that the university president is the main pillar in the scheme of any university that 
wants to join the elite club in the world. The university president is its window to the world.

And in the last rank is "strategic planning". This may be attributed to the fact that strategic planning is linked to the vision that the university seeks to achieve through the application of legislation, regulations and instructions that lead to the required results.

The researcher believes that strategic planning is related to all classification criteria, as the importance ratio came to 4.58. It is high, but not of the required level.

Discussing the results related to the answer to the third question: What is the degree of need to provide classification criteria for universities at the University of Jordan based on the difference between the degree of availability and the degree of importance attributable to the variable of job rank? The results were as follows:

- The results showed that there are no statistically significant differences at the level of significance $(\alpha \leq 0.05)$, due to the fact that all academic administrators at all levels perceive the need to provide classification criteria for universities at the University of Jordan.

The results of this study are consistent with Barakat's study (2016).

\section{RECOMMENDATIONS:}

In light of the findings of the study, the researcher concludes with presenting a set of recommendations:

1. The results of the first question showed that the study sample's estimates of the degree to which university classification criteria are available at the University of Jordan "as a whole" was of a medium degree in the field of "external focus", the field of "strategic planning", and the field of "information and its analysis." The researcher recommends:

Issuing an introductory yearbook of the University of Jordan and its achievements.

* Empowering leaderships at the University of Jordan for strategic planning.

* Establishing information incubators in which to make use of the available information. It is intended to create centers within universities that transform available information into innovations with the help of students, through the establishment of small projects that transform the university into a productive university.

2. The researcher recommended conducting other studies in the field of classification of Jordanian universities.

\section{REFERENCES}

[1] Barakat, Ziyad (2016). Proposals for Preparing Palestinian Universities for International University Classification, Journal of the Association of Arab Universities for Research in Higher Education, 36 (1): 124.

[2] World Bank, (2010). Reviews of National Education Policies Egypt: Organization for Economic Cooperation and Development.

[3] Houria, Ali Hussein (2013), The Reality of Planning to Prepare Taibah University to Achieve Global University Ranking Policies, Journal of the Association of Arab Universities for Research in Higher Education, 33 (4): 149-182.

[4] Sayegh, Abd al-Rahman (2011). International University Rankings: The Experience of Saudi Universities, The Saudi Journal of Higher Education, 5: 52-38.

[5] Siddiqui, Saeed (2015). Arab Universities Site in International University Rankings: Critical Reading, Journal of Universities and Scientific Research in the Arab World - Qatar, 5 (16): 18-35.

[6] Al-Abbad, Abdullah (2017). A proposed model to raise the competitiveness of King Saud University in light of the standards of international university rankings, The International Journal of Specialized Education, 6 (1): 306-326.

[7] Ghaboub Yacouta (2016). The reality of Jordanian universities in the international classification: Algeria as a model, Journal of Economics and Human Development - Algeria, 13: 336-348.

[8] Carroll, D. (2014). An investigation of the relationship between university rankings and graduate starting wages. Journal of Institutional Research, 19 (1), 46-54.

[9] Isidro, f \& Agullio, w (2008). Webometrics and the Ranking of Universitie

[10] Madrid, Spain: CSIC. Luke.M \& Robe. (2009) College Ranking History, Criticism and Reform, Washington: CCAP Center for College Affordability.

[11] Salmi, J. (2013). Daring to Soar: A Strategy for Developing World-Class Universities in Chile. Educational Latin-American, 50 (1), 130- 146.

[12] Sheil, T. (2010). Moving beyond university rankings: Developing a world class university system in Australia. Australian Universities' Review, 52 (1). 69-76.

[13] Times News. Times Higher Education World University Rankings of (2016-2017), retrieved (22-3-2018) from https://www.timeshighereducation.com/world-universityrankings.

[14] Webometrics of World Universities Ranking. (2016). Webometrics of World Universities Ranking, retrieved (22-3-2018) from: https://www.webometrics.info/en/world.

[15] Wildavsky, B. (2010). The Great Brain Race: How Global Universities are

[16] Reshaping the World. (Princeton \& Oxford: Princeton University Press. 